\title{
FILLED PAUSES IN MODERN IRISH
}

\author{
MARINA SNESAREVA
}

In every language there are different types of pauses, which are generally divided into filled and unfilled ones (Trouvain 2004: 27). The latter type either consists of silence or is phonetically filled with breathing, whereas in the former so-called 'fillers' of different kinds are used (separate sounds, syllables and even whole words). Spontaneous speech in Modern Irish is marked by the extensive use of both pause types, and though there are cases where pauses can be described as a hesitation phenomenon only, their use may also be connected with information status, new data being enhanced and highlighted by the pause (Trouvain 2004).

In Modern Irish filled pauses occur quite frequently in spontaneous speech, and here it is the placement of pauses that appears to be of particular interest. Thus, for example, in Connacht Irish the majority of filled pauses occur on the phrase border, directly preceding the following utterance, which can be accounted for by the fact that in such speech the process of formulating thoughts takes place at the very moment of speaking. Pauses are thus introduced to provide the speaker with some additional time to formulate the next utterance or its part.

As filled pauses not infrequently occur on the phrase border, it is not uncommon for the verb to be chosen as the pause filler. This can be partly explained by the word order in the Irish sentence (VSO), where it is the verb that usually takes the initial position. In these cases auxiliary verbs are often used, such as different forms of the verb 'to be' tá, bhi and the copula is, an. Consider, for example, the following sentence, where the present tense form of copula is repeated:

${ }^{1}$ Bhuel, déarfainn... ${ }^{2}$ is...is...is... (570 ms) ceist polaitíochta atá ann, ${ }^{3}$ dar ndóigh.

${ }^{1}$ Well, I would say ${ }^{2}$ it's... it's a political question, ${ }^{3}$ actually.

Some other examples include the repetition of the definite article, which can take place in emphatic constructions, the noun being brought forward and placed at the beginning of an utterance, as in the following example:

${ }^{l}$ An...an... (500ms) an rud ${ }^{2}$ a bhí muid ag iarraidh a dhéanamh ${ }^{3}$ leis na leabhra seo...

${ }^{1}$ What [lit. the thing $]^{2}$ we were planning to do ${ }^{3}$ with these books... 
Here we are provided with the initial part of the utterance only (the emphatic construction itself and the close), the whole phrase being much longer. As we can see from the example, the definite article an is repeated several times, thus providing the speaker with approximately $500 \mathrm{~ms}$ extra time to formulate the beginning of the utterance.

It should be noted here that filled pauses may also occur inside a compound or complex sentence, that is, on the border between its selfcontained parts. If the next part of the utterance begins with a conjunction or a preposition, it is this word that commonly acts as a pause filler, for example:

${ }^{1}$ An chéad Ard Fheis ceart ${ }^{2} a$ bhí againn ${ }^{3}$ ó...ó...ó... (1780ms) ó cuireadh amach ${ }^{4}$ as an Rialtas muid.

${ }^{1}$ The first real Ard Fheis ${ }^{2}$ we had ${ }^{3}$ since... since we were excluded ${ }^{4}$ from the Government.

Thus, the number of different pause fillers may vary and is by no means confined to auxiliary verbs only. The present study has been conducted on the basis of one of the main Irish dialects (Connacht Irish), the material used including spontaneous speech samples of different length, produced by native speakers. These samples were predominantly extracted from Raidió na Gaeltachta podcasts, especially the Iris Aniar programme (2012-13).

The chosen dialogues, their total speaking time amounting to over 250 minutes, were analysed descriptively with the help of Praat (Boersma \& Weenink 2009), which enabled me to measure the articulation rate and the duration of pauses as well as to define prosodic and pause boundaries more precisely. These results, however, have been tested on one Irish dialect only (Connacht Irish), and in order for a plausible conclusion about languagespecificity of filled pauses usage to be reached spontaneous speech samples of the other Irish dialects (Munster and Ulster Irish) should be studied and compared as well in future research.

Lomonosov Moscow State University

\section{References}

Boersma, P., Weenik, D., 2009, Praat: Doing Phonetics by Computer [computer programme]. http://www.praat.org/

Trouvain, J., 2004, Tempo Variation in Speech Production, Saarbrücken. 